\title{
Erratum
}

\section{Passivity-Based Attitude Control on the Special Orthogonal Group of Rigid-Body Rotations}

\author{
James Richard Forbes \\ University of Michigan, Ann Arbor, Michigan 48109-2140 \\ [J. Guidance, 36(6), pp. 1596-1605, 2013] \\ DOI: 10.2514/1.G00051010.2514/1.G000510; published online 21 April 2014.
}

The author of [1] acknowledges [2] for a clear and methodical exposition leading to their control law (20) and (21). A similar exposition in [1] leads to the controller (18). This addendum is intended to correct the omission of [2] from the bibliography in [1] ].

\section{References}

[1] Forbes, J. R., "Passivity-Based Attitude Control on the Special Orthogonal Group of Rigid-Body Rotations," Journal of Guidance, Control, and Dynamics, Vol. 36, No. 6, 2013, pp. 1596-1605. doi: $10.2514 / 1.59270$
[2] Khosravian, A., and Namvar, M., "Rigid Body Attitude Control Using a Single Vector Measurement and Gyro," IEEE Transactions on Automatic Control, Vol. 57, No. 5, 2012, pp. 1273-1279. doi:10.1109/TAC.2011.2174663 
This article has been cited by:

1. Quan Hu, Xiao Feng, Xiangyuan Zeng, Jingrui ZhangPassivity Control with Practical Finite-time Convergence for Large Space Structures . [Citation] [PDF] [PDF Plus] 